\title{
A monitoring framework based on exergetic analysis for sustainability assessment of direct laser metal deposition process
}

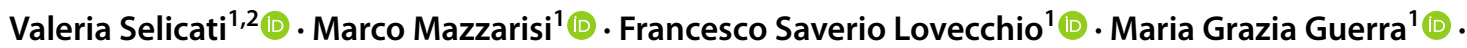 \\ Sabina Luisa Campanelli ${ }^{1}$ - Michele Dassisti ${ }^{1}$.
}

Received: 5 March 2021 / Accepted: 4 October 2021 / Published online: 16 October 2021

(c) The Author(s) 2021, corrected publication 2022

\begin{abstract}
With the constant increase of energy costs and environmental impacts, improving the process efficiency is considered a priority issue for the manufacturing field. A wide knowledge about materials, energy, machinery, and auxiliary equipment is required in order to optimize the overall performance of manufacturing processes. Sustainability needs to be assessed in order to find an optimal compromise between technical quality of products and environmental compatibility of processes. In this new Industry 4.0 era, innovative manufacturing technologies, as the additive manufacturing, are taking a predominant role. The aim of this work is to give an insight into how thermodynamic laws contribute at the same time to improve energy efficiency of manufacturing resources and to provide a methodological support to move towards a smart and sustainable additive process. In this context, a fundamental step is the proper design of a sensing and real-time monitoring framework of an additive manufacturing process. This framework should be based on an accurate modelling of the physical phenomena and technological aspects of the considered process, taking into account all the sustainability requirements. To this end, a thermodynamic model for the direct laser metal deposition (DLMD) process was proposed as a test case. Finally, an exergetic analysis was conducted on a prototype DLMD system to validate the effectiveness of an ad-hoc monitoring system and highlight the limitations of this process. What emerged is that the proposed framework provided significant advantages, since it represents a valuable approach for finding suitable process management strategies to identify sustainable solutions for innovative manufacturing procedures.
\end{abstract}

Keywords Additive manufacturing · Direct laser metal deposition · Exergetic analysis · Thermodynamic model · Monitoring system $\cdot$ Sustainable manufacturing

\begin{tabular}{|c|c|c|c|}
\hline & menclature & $\eta$ & Exergy efficiency [\%] \\
\hline c & Specific heat $[\mathrm{J} / \mathrm{kg} \mathrm{K}]$ & $\mathrm{AM}$ & Additive manufacturing \\
\hline$\dot{m}$ & Mass flow rate $[\mathrm{kg} / \mathrm{s}]$ & CERA & Cumulative energy requirements analysis \\
\hline Ex & Exergy $[\mathrm{J}]$ & DLMD & Direct laser metal deposition \\
\hline$\dot{E} x$ & Exergy flow $[\mathrm{W}]$ & EA & Exergetic analysis \\
\hline $\mathrm{h}$ & Specific enthalpy $[\mathrm{J} / \mathrm{kg}]$ & LCA & Life cycle assessment \\
\hline$\dot{H}$ & Enthalpy flow rate [W] & MFA & Material flow analysis \\
\hline$\dot{Q}$ & Heat transfer rate $[\mathrm{W}]$ & Subscrip & ts and superscripts \\
\hline$\overline{\mathrm{S}}$ & Specific entropy [J/kg K] & 0 & Dead state \\
\hline $\begin{array}{l}\mathrm{T} \\
\dot{W}\end{array}$ & Temperature $[\mathrm{K}]$ & $\mathrm{c}$ & Number of total enthalpy flows \\
\hline W & Workflow rate $[\mathrm{W}]$ & $\mathrm{d}$ & Number of total workflows \\
\hline & & $\mathrm{e}$ & Equilibrium \\
\hline$\square$ & Marco Mazzarisi & eq & Equivalent \\
\hline & marco.mazzarisi@poliba.it & $\mathrm{g}$ & General \\
\hline & & $\mathrm{i}$ & State point at the inlet of system/sub-system \\
\hline & Politecnico Di Bari, Via Edoardo Orabona 4, 70126 Bari, & $\mathrm{k}$ & Number of total mass flows \\
\hline 2 & Università Degli Studi Della Basilicata, Via Lanera 20, & $\begin{array}{l}\text { loss } \\
n\end{array}$ & $\begin{array}{l}\text { Flow rate loss during the sub-processes } \\
\text { Net use }\end{array}$ \\
\hline
\end{tabular}


o State point at the outlet of system/sub-system

$\mathrm{p} \quad$ Number of total heat transfer flows

tot Total of useful and wasted energy flows

\section{Introduction}

The focus on digitalization, process technology innovation, and sustainability has increased exponentially within the Industry 4.0 paradigm (I4.0 from now on) [1]. The recent introduction of disruptive innovative technologies and infrastructures, such as the Internet of Things and Cyber Physical Systems, is leading to new organizational, technological, and eco-compatible challenges in manufacturing contexts [2].

Among the Key Enabling Technologies of I4.0, additive manufacturing (AM) is considered a key factor for the implementation of a new production paradigm [3, 4]. In the Factory 4.0 ecosystem, AM plays an important role among the advanced manufacturing systems for the development of prototypes or for producing customized components. The concurrent development of hardware, software, and the intense research for adopting new materials (metals, polymers, ceramics, and multi-material composites) has been the key to success of AM technologies, leading to an expansion of the application fields. Currently, aerospace, automotive, biomedical, and digital architectural design are the industrial sectors with the greatest interests towards AM processes [5], although these sectors are not inclined to accept process failure or low-quality products. In this context, the development of adequate monitoring systems is strictly connected to the increase of reliability of the AM processes, in order to achieve stable and effective process conditions.

The value of sensing and monitoring systems for I4.0 has been accepted and acknowledged by various authors, as stated in [6]. Similar to the fourth industrial revolution, Peter Krause coined the term "Sensor 4.0" to indicate the evolution of this technological field (in chronological order: mechanical sensors, electrical sensors, electronic sensors, and smart sensors), remarking the idea of how measurement systems have been influenced by the industrial evolution [7]. Sensors are the enabling elements to build up a framework for the assessment of the sustainability of manufacturing technologies, in terms of technical quality of products and environmental compatibility of processes.

Regarding the sustainability of AM technologies, these are typically seen as "cleaner" than traditional manufacturing processes. In fact, these comply with some of the sustainability principles [8] such as "reducing" or "redesigning" and other benefits related to potential social impacts, such as new opportunities from the circular economy. Although, according to several studies, sustainability of AM technologies is not always assured "tout court" [9], it should be assessed from different perspectives in order to consider all process aspects comprising machine tool life cycle, tooling supply chain, energy management, product usage impacts, end-of-life issues, recycling rates, disposal costs, pollutions, etc. Various approaches have been developed over the years to encourage the sustainability evaluation of the abovementioned aspects of manufacturing processes [10]. With such a diverse spectrum of developing technologies, it is critical to examine which techniques are most suited for qualitative and quantitative assessing of their sustainability. Among these, models based on thermodynamic analyses represent an innovative and interesting strategy for analyzing and maximizing the sustainability of the manufacturing system performances, facilitating the management of smart manufacturing processes.

In this work, this topic is addressed by focusing on the technology, on the integrated sensing and monitoring system to be designed, and on the simulation and modelling techniques to gather knowledge from the disaggregated data provided by the sensor network. The aim of this work is to give an insight into how thermodynamic laws can help improving energy efficiency and at the same time provide a methodological support to move towards a smart sustainable process. The strategy concerns the design of a realtime monitoring framework for the direct laser metal deposition (DLMD) process, beginning with the description of its overall technological aspects and the definition of the thermodynamic model for the sustainability requirements. The DLMD is an advanced AM process mainly employed in high-technological industrial fields [11]. Principally used for repairing and remanufacturing of worn components, it is recently being exploited to produce 3D parts made with numerous metallic materials from scratch [12].

To this end, the exergetic analysis (EA) has been considered the most suitable approach among the variety of methods for sustainability assessing. EA is a non-linear methodology that addresses information about the efficiency of the energetic and raw material resources consumption and the potential for improvement [13]. This method is gaining popularity because it attempts to overcome the most significant limitations of the most popular methods. Among all, there is the life cycle assessment (LCA) that is the widely used linear method for assessing a broad spectrum of environmental impacts, including the intensity of consumed material and energy, throughout the entire life cycle of the process [14]. It should be emphasized that, to date, no such thermodynamic modelling approach has been applied to the DLMD process in the literature, which makes this work a novelty.

The most crucial point of the sustainability assessment is the definition and collection of a comprehensive set of parameters and associated cause-effect relationships for an effective monitoring of the addressed process [15]. It means that a wide knowledge about all data related to materials, energy, machinery, and auxiliary equipment is mandatory 
to optimize the overall process performances. With this aim, the integration of an appropriate sensing and monitoring system into industrial machines is essential. Finally, the amount of technological data collected in ad-hoc structured datasets allows addressing the problem of prognostic health management with a multi-model approach [16]. In particular, it can be achieved through the interoperability between a physicsbased model, a knowledge-based model, and a data-driven model, structuring the process knowledge for assuring a correct transition towards the smart manufacturing modelling of I4.0.

The rest of the paper is organized as follows. In Section 2, a brief state of the art about technological features and sustainability assessment of the DLMD technology is provided. The criteria under which the DLMD process has been modelled are also addressed. It also provided a short overview of the potential sensing systems for real-time state monitoring of dynamic manufacturing processes. The test case, concerning the EA of a single-track deposition realized by means of the prototype DLMD system, is addressed in Section 3. Conclusions and further developments close the paper.

\section{State of art of technological and sustainable modelling of DLMD}

\subsection{DLMD technology}

The DLMD is a sub-category of the family of technologies named direct energy deposition (DED), in which a laser is employed as energy source. The laser beam is focused on a metal substrate generating very high temperatures that lead to the melting of the interested region of the workpiece. Material is added in the molten pool in form of wire or powder. The latter is conveyed by means of an inert carrier gas ( $\mathrm{Ar}, \mathrm{He}, \mathrm{N}_{2}$ ), which is also used to shield the molten pool from oxidation. By moving a nozzle, a single-track deposition is created and, by following specific paths and strategies, the final component is built layer by layer. The extremely high-power density of the laser determines exceptional metallurgical properties. The temperature management during the process is a key feature to achieve an acceptable quality of the component and to improve the process efficiency. As other AM technologies, several materials can be processed by DLMD such as steel alloys, aluminum alloys, titanium alloys, nickel alloys, and superalloys. The DLMD involves many process parameters and a careful design is required for obtaining components in compliance with high-performance standards $[17,18]$.

In order to develop an in-depth sustainability analysis of the technology, an accurate description of the main parts composing the DLMD system is required. The core of the system is the laser source that can be classified by the active medium used to generate the laser beam. All of these sources have relatively low efficiencies, converting a large amount of electrical energy into wasted heat, which may compromise the operation of the laser source. Thus, heat exchangers and chillers are adopted to favor the heat diffusion into the environment [19].

The filler material is usually supplied by means of specific powder feeders to dose and preheat the powders. These are transported by a carrier gas through a pipe system to the end part of the deposition head. The toolpaths are executed by means of 3- or 5-axis CNC machines or, in the most recent configurations, by anthropomorphic robots [20].

The environment in which the system operates must be isolated by a working chamber in order to protect the operator from damage caused by laser reflections or powder contaminations. The internal environment, when contaminated by powders and gases, must be cleaned by means of suction and filtering systems at the end of the processing.

The whole system is managed and supervised by one or more on-board computers. The monitoring of such a complex system and process is usually carried out through various sub-systems, which will be discussed in more detail in the next section.

\subsection{Sustainability assessment of additive manufacturing technology}

The sustainability paradigm is now widespread in any technological sector $[8,11,21,22]$. In the literature, various methods and approaches have been considered to be suitable for assessing the sustainability of AM processes. In this section, a brief description of these methods and an overview of the state of the art of such applications in the AM field are carried out; see [23] for more details. The critical issues of each method were highlighted to prove the effectiveness of the method proposed in this work, which focuses on thermodynamic analysis with the EA. In our work, we consider the proposed procedure as the best method to reach the goal of demonstrating the effectiveness of the thermodynamic model in an ad-hoc design of a sensing and monitoring system for the DLMD technology, in order to improve the process sustainability.

The material flow analysis (MFA) is a systematic examination of flows and stocks of materials within a space-timedefined system [24]. It connects material sources, routes, intermediate, and ultimate sinks. However, the method focuses only on material flows, not considering and evaluating any energy flows related to the process.

Alternatively, the cumulative energy requirements analysis (CERA) estimates the whole demand for primary energy that emerges in connection with the production, consumption, and disposal of an economic good (product or service) or that can be attributed to it in a causal relationship 
[25]. This energy requirement is the whole of the cumulative energy requirements for manufacturing, consumption, and disposal of the economic good. The CERA calculation results are typically derived as ultimate energy consumption. The correct determination of the balancing limits is a crucial basis for calculating the CERA. Because of the great complexity and diversity of individual process interactions, systematic delimitation is usually a fundamental challenge in energy analysis.

The LCA is a standardized tool for the assessment of the environmental impact of products, processes, and activities [14]. According to ISO 14040 [26], it consists in inventorying energy and mass input and output flows and in the assessment of their potential harm to the environment throughout the entire life cycle of a process or product [27]. Although it is subject to standard databases, a limitation of ISO standards is their generic nature: greater contextualization or a series of exemplary test cases would be preferable to avoid free interpretations. About LCA in the AM sector [28], the literature makes no mention of process modelling via LCA $[29,30]$. The case studies consist in a comparison of alternatives for decision-making to choose the most sustainable solution for the considered process [31] or in a discussion on advantages and disadvantages of AM technologies [32]. Although AM is considered a more environmentally friendly process than traditional manufacturing systems, there are not enough LCA studies to prove it and to highlight that this technology is still little explored. A research involving a technique roughly similar to the one that will be used in this paper is presented in [33], where a process unit level model is created to provide a complete parametrical life cycle inventory for a further LCA of the AM process.

Exergy is defined as the maximum work that can be provided by a system when it reaches the thermodynamic equilibrium with reference environment conditions through a sequence of reversible processes occurring between the considered system and its surrounding environment [34]. During the process, a part of the exergy is consumed or lost due to its irreversibility [35]. The EA in a manufacturing system aims to reveal the improvement potential, while the exergy efficiency is an important parameter for the assessment of the sustainability of a manufacturing process [36]. When approached in this way, the concept of sustainability becomes a matter of thermodynamics. There are also methods that combine EA and LCA in various ways, as described in [37]. Few works on the application of EA approaches on AM technologies have been found in the literature. The first consists of an Em-LCA implementation for AM sustainability evaluation [38]. Critical problems and possible improvements are identified, but only from a sustainability perspective. Nagarajan and Haapala [39] attempted to identify and characterize the factors affecting the systemic environmental performance of AM, using EA, LCA, and cumulative exergy demand (CExD, an hybrid method between the both) for the final use of energy [40]. Nevertheless, there is no mention on prospective process modelling.

Based on this brief overview of the state of the art, it is possible to assert that the EA approach, aided by a thermodynamic modelling of the process, can highlight the peculiarities of the AM technology. It provides a more in-depth sustainability assessment and indicates how to improve sustainable performances. Moreover, this approach is not yet found in the literature and has not yet been applied to DLMD technology. In the following paragraph, the above mentioned modelling is analyzed more in detail.

\subsection{The thermodynamic modelling: theory and calculation}

This section explains how to define the set of parameters to be monitored, as well as the requirements for designing an ad-hoc framework to monitor the manufacturing process. As already introduced, the selected model-based approach among the I4.0 modelling techniques is the EA. This combined model enables the process to be efficiently split into functional units, which have to be adequately analyzed in order to determine the critical unit and to monitor the state of the key parameters.

With regard to the state of the art illustrated in Section 2.2, this approach is entirely innovative because EA primarily aids to define a model or a set of parameters that can be useful to extract hidden knowledge about the dynamics of the process. Ultimately, it provides an estimation of the quality of the process (in terms of efficiency) and of the possible environmental impacts caused by the mere consumption of resources and energy. In the literature, only EA, or even LCA, are used as sustainability metrics but no one has applied this approach to any $\mathrm{AM}$ process to date.

Considering a basic control volume for a generic manufacturing process, Fig. 1 shows a conceptual scheme of the main input and output flows (materials, energy, etc.) that can occur.

The first and second laws of thermodynamics state the foundation of EA. The first law covers energy conservation, whereas the second law describes the quality of energy and materials. These thermodynamic laws behind the EA are fundamental to trace the set of parameters that need to be measured and monitored during the process, as well as the variables that can be calculated. Basing on Szargut's studies [41], reference flows can be uniquely identified in the following balance equations.

Mass flow balance in Eq. (1) describes the balance for the considered system of in and out materials flows.

$\sum_{k} \dot{m}_{k}^{i}=\sum_{k} \dot{m}_{k}^{o}$

Energy flow balance is reported in Eq. (2). Energy is an extensive variable and therefore the energy of a system in a given state equals the sum of the energies of all sub-systems 
Fig. 1 Control volume of a generic manufacturing process

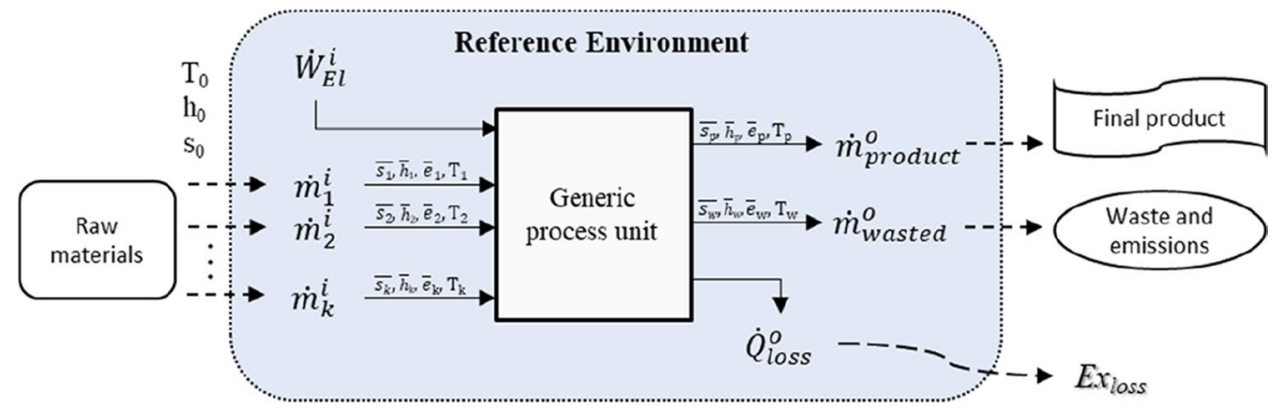

that can be identified as a part of a given system [42]. When considering an isolated system, its total energy content cannot change as stated in the first law of thermodynamics: energy is conserved [43]. As a result, energy can only be changed or converted from one kind to another, but the loss of quality of energy is not taken into account. All the outcoming heat flows have been considered within the last term in Eq. (2), which represents the sum of all the heat sources necessary for the process and the wasted heat. An EA must be done to identify and quantify the irreversibility. To do this, closed material and energy flow balance with energy interactions (work and heat) between inbound and outbound flows from the system boundaries must be carried out.

$\sum_{c} \dot{H}_{c}^{i}+\sum_{d} \dot{W}_{d}^{i}+\sum_{p} \dot{Q}_{p}^{i}=\sum_{c} \dot{H}_{c}^{o}+\sum_{d} \dot{W}_{d}^{o}+\sum_{p} \dot{Q}_{p, t o t}^{o}$

Exergy flow balance is stated in Eq. (3). The concept of equilibrium is often questionable since it is not observable or even possible in nature. Exergy, unlike energy, is not conserved. It is instead consumed or destroyed to some amount in any real process. As a result, by accounting for all of the exergy streams in the system, the amount to which the system destroys exergy may be determined. The exergy loss is proportional to the entropy generated; the destroyed exergy, or produced entropy, is accountable for the less-than-theoretical efficiency of the system. The exergy destruction rate $\left(\dot{E}_{x_{\text {loss }}}\right)$ may be determined by balancing the exergy between inbound and outbound flows when work is exchanged, or heat transfers occur.

$\sum_{c} \dot{E} x_{c}^{i}+\sum_{d} \dot{W}_{d}^{i}+\sum_{p}\left(1-\frac{T_{0}}{T_{e}}\right) \dot{Q}_{p}^{i}=\sum_{c} \dot{E} x_{c}^{o}+\sum_{d} \dot{W}_{d}^{o}+\sum_{p}\left(1-\frac{T_{0}}{T_{e}}\right) \dot{Q}_{p}^{o}+\dot{E} x_{l o s s}$

where in $\left(1-\frac{T_{0}}{T_{e}}\right), T_{0}$ is the reference temperature of the dead state and $T_{\mathrm{e}}$ is the equilibrium temperature, as described in Eq. (4).

$T_{e}=\frac{T_{k}^{i}+T_{k}^{o}}{2}$

The enthalpy flow rate (Eq. (5)), the specific entropy (Eq. (6)), and the exergy (Eq. (7)) are calculated respectively:
$\dot{H}=\dot{m} \bullet c \cdot\left(T-T_{0}\right)$

$\bar{s}=c \cdot \ln \left(\frac{T}{T_{0}}\right)$

$\dot{E} x=\dot{m} \bullet\left[\bar{h}-\bar{h}_{0}-T_{0} \bullet\left(\bar{s}-\bar{s}_{0}\right)\right]$

The performance metrics of the process or its components are described in the following net and general efficiencies (Eqs. (8) and (9), respectively), depending on whether the objective is to evaluate the portion of useful exergy for the realization of the final product or to evaluate the overall exergy of the process:

$\eta_{n}=\frac{\sum E x^{\text {product }}}{\sum E x^{\text {in }}}$

$\eta_{g}=\frac{\sum E x^{\text {out }}}{\sum E x^{\text {in }}}$

Other types of information, such as upstream processes for the supply of raw materials and resources needed for the process and downstream processes about emissions treatments and waste scenarios, have been neglected in this assessment. The optimization criteria involve the minimization of the term $\mathrm{Ex}_{\text {loss }}$ that is the cause of the less-thantheoretical efficiency of the process. Temperature variations play a key role in the exergetic equilibrium. The greater the disparity in temperatures in two transition phases, the greater the energy produced.

The energy balance in Eq. (2) is also important in terms of product quality optimization. A very illustrative example can be the one in [44] where the authors concluded that energy is linked to the thickness of the finished product through an inverse proportion. This means that energy analysis makes possible at the same time to increase the quality of the finished product, to control its characteristics and to reduce the energy costs of the process [45].

According to the EA data inventory of the overall DLMD process, the set of essential thermodynamic parameters to be 
measured (M) and those calculated (C) by means of thermodynamic laws are shown in Table 1.

\subsection{Sensing systems for monitoring of AM processes}

As stated in the AM roadmap [46], one of the most challenging goals for scientists is the in situ real-time monitoring of AM parameters. In the last years, the development of inprocess monitoring methods has enhanced the final quality of AM products and, consequently, the possibility to adopt AM technologies for high-value applications where component failure cannot be tolerated. Actually, the in-process monitoring allows achieving a clear picture of physical, thermodynamic, and mechanical behaviors of AM processes, thus improving energy and technological performance and being the keystone to find a compromise between technical quality and sustainability [8].

This is achieved by directly measuring deposition characteristics (temperatures, melting pool size, track height, etc.; see Section 2.1) during the process and by correlating all of them to the input process parameters [47]. Several monitoring methods are adopted, both through thermal measurements and via visible light-based measurements, which can have different configurations. In literature, the sensing systems for DLMD processes mainly focus on in situ monitoring of the melt pool in terms of temperature and size [48, 49], sensors to monitor material flow rate, and in situ monitoring of the clad geometry (height and width) [50,51].

All the abovementioned monitoring methods and instruments are necessary for a better understanding of the process dynamics as well as for the implementation of adaptive and closed-loop control systems [52]. However, these are often investigated separately, providing only partial information about the process under the selected operating conditions. Moreover, the abovementioned parameters and the corresponding monitoring tools are more focused on the process performances in terms of quality of the final product, often disregarding other aspects such as the environmental issues.
The ideal approach should consider, then, an integration between quality and environmental aspects. This is achieved by combining different types of information derived from specific acquisition devices such as in situ images, clad profiles, and temperatures, as well as material and energy flows, in other words, a multi-sensor and holistic approach based on geometrical, thermal, and environmental controls [53].

The monitoring system proposed in the present work is based on a multi-sensor approach capable to acquire the most relevant information for the thermodynamic model and exergy analysis, but also relevant information about the quality of the process. This is the main advantage of the proposed approach with respect to other conventional monitoring practices. To encourage and make easier such a multi-sensor approach, a suited hardware and software platform is needed, which is capable to acquire and synchronize data coming from different sources both on-line and off-line. The choice of a multi-sensor platform is not a trivial task, as it needs to be carefully evaluated. Several commercial data acquisition device (DAQ from now on) systems are available from National Instruments (NI), DEWESoft, dSpace, Microstar Laboratories, MCCDAQ, and many others. An example of a NI acquisition board is presented in [54].

As an alternative to commercial DAQ systems and thanks to the development of open source software and low-cost hardware, researchers have the opportunity to realize selfmade custom acquisition systems, as reported in [55] where a low-cost multi-sensor acquisition platform based on Arduino has been used for the monitoring of a wire-arc AM manufacturing process.

In this context, both Python and Raspberry have recently increased their popularity [56]. Worldwide communities constantly support the development of Raspberry [57] and Python scientific [58] applications. A monitoring system based on the combination of both can represent a reasonable choice to realize a sensing framework for the DLMD, where a high technological flexibility, to deal with devices of different manufactures, and the implementation of on-line and off-line elaboration algorithms are required. Anyway, this
Table 1 Essential thermodynamic parameters of DLMD process

\begin{tabular}{|c|c|c|c|c|c|}
\hline Material/energy & Parameter in & Variable & Parameter out & Variable & $\mathrm{M} / \mathrm{C}$ \\
\hline \multirow[t]{2}{*}{ Metal powder } & Mass flow $[\mathrm{kg} / \mathrm{s}]$ & $\dot{\mathrm{m}}_{\text {Powder }}^{\text {in }}$ & Mass flow $[\mathrm{kg} / \mathrm{s}]$ & $\dot{\mathrm{m}}_{\text {Powder }}^{\text {out }}$ & M \\
\hline & Temperature $[\mathrm{K}]$ & $\mathrm{T}_{\text {Powder }}^{\text {in }}$ & Temperature $[\mathrm{K}]$ & $\mathrm{T}_{\text {Powder }}^{\text {out }}$ & M \\
\hline \multirow[t]{2}{*}{ Gases } & Volume flow [1/s] & $\dot{\mathrm{m}}_{\text {Argon }}^{\text {in }}$ & Volume flow $[1 / \mathrm{s}]$ & $\dot{\mathrm{m}}_{\text {Argon }}^{\text {out }}$ & M \\
\hline & Temperature $[\mathrm{K}]$ & $\mathrm{T}_{\text {Argon }}^{\text {in }}$ & Temperature $[\mathrm{K}]$ & $\mathrm{T}_{\text {Argon }}^{\text {out }}$ & M \\
\hline \multirow[t]{2}{*}{ Cooling fluid } & Volume flow [1/s] & $\dot{\mathrm{m}}_{\mathrm{H} 2 \mathrm{O}}^{\mathrm{in}}$ & Volume flow $[1 / \mathrm{s}]$ & $\dot{\mathrm{m}}_{\mathrm{H} 2 \mathrm{O}}^{\text {out }}$ & M \\
\hline & Temperature $[\mathrm{K}]$ & $\mathrm{T}_{\mathrm{H} 2 \mathrm{O}}^{\mathrm{in}}$ & Temperature $[\mathrm{K}]$ & $\mathrm{T}_{\mathrm{H} 2 \mathrm{O}}^{\text {out }}$ & M \\
\hline Electricity & Electric power [W] & $\dot{\mathrm{W}}_{\mathrm{el}}$ & & & M \\
\hline Heat & & & Heat loss [W] & $\dot{\mathrm{Q}}_{\mathrm{loss}}$ & $\mathrm{C}$ \\
\hline Exergy & & & Exergy loss [W] & $E x_{\text {loss }}$ & $\mathrm{C}$ \\
\hline
\end{tabular}


approach can also be complementary and integrated with standard scientific NI acquisition boards [59] and MATLAB algorithms [60].

In conclusion, in order to prove to be well suited for the proposed holistic multi-sensor approach, the architecture of the monitoring system should combine the capabilities of all sensing units and at the same time be effective in terms of flexibility and adaptability.

\section{Test case: materials and methods}

The AM process addressed to prove the effectiveness of the above-described approach is the DLMD. Figure 2a shows a schematic representation of the prototype system located at the Polytechnic University of Bari, consisting of the following:

- A fiber laser source with a nominal power of $4 \mathrm{~kW}$ and a wavelength of $1.070 \mu \mathrm{m}$ (YLS 4000 IPG Photonics Ytterbium Laser System)

- A 5-axis machine equipped with a deposition head and a coaxial nozzle

- A $11.57-\mathrm{kW}$ chiller system for the laser source (chiller for core from now on)

- A 1.4-kW chiller system for the nozzle and the optics (chiller for nozzle from now on)

- A 600-W chiller system for the fiber optics cables (chiller for fiber from now on)

- An external pre-heated powder feeder
- A 2.2-kW powder suction system and a gravimetric dispenser

In order to protect operators and avoid environmental pollution, the working area is surrounded by a glove-box chamber. Inside it, in addition to the laser deposition head shown in Fig. 2b, monitoring systems such as a coaxial camera and a pyrometer are also located. For the purpose of this work, an AISI 316L stainless steel powder was deposited on a substrate of the same material. Argon was employed as carrier gas for the powder and as shielding gas to prevent clad oxidation. In order to assess the feasibility of the proposed thermodynamic model and monitoring framework, a single-track deposition was realized as represented in Fig. 2c. Single-track depositions are the basis of the most complex deposition patterns, and their analysis is crucial for the DLMD process. The main process parameters used for the deposition test were chosen basing on a previous work on the feasibility of DLMD [61], which explored different materials and setups, and are shown in Table 2.

\subsection{The thermodynamic model of DLMD system}

The thermodynamic model of the prototype DLMD system was developed starting from the guidelines provided in Section 2.3 and also its optimal sub-unit partitioning and all the specific in and out flows have been established. The model results in a set of parameters that can be monitored in real time or at a sampling rate high enough to identify trends in energy/exergy consumption and losses that make the process less efficient and less sustainable.
Fig. 2 a Schematic representation of the prototype DLMD, $\mathbf{b}$ deposition head, and $\mathbf{c}$ singletrack deposition

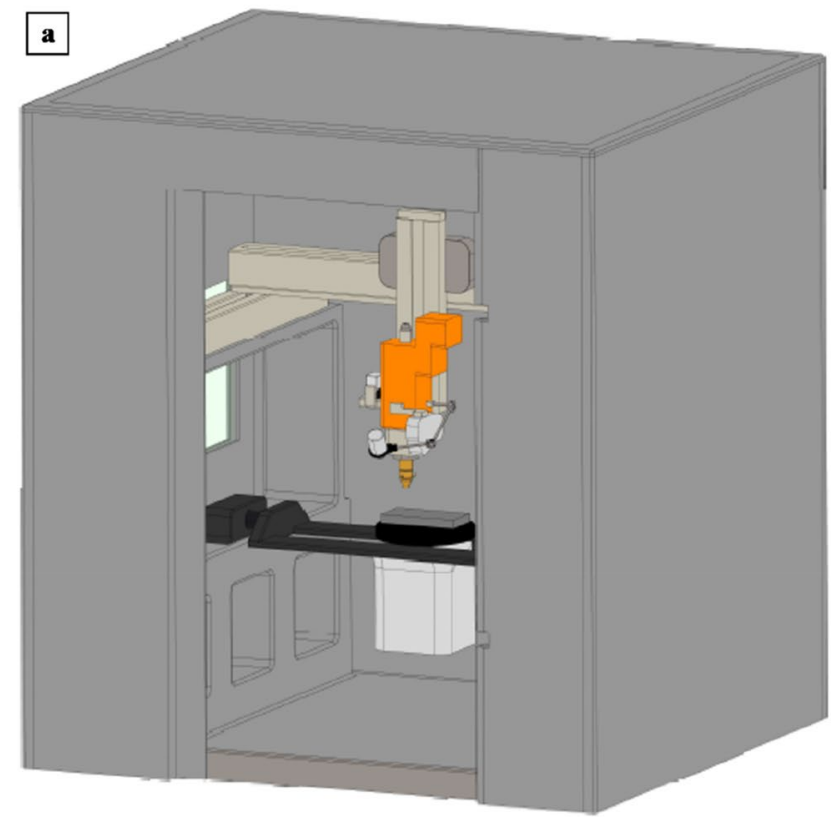

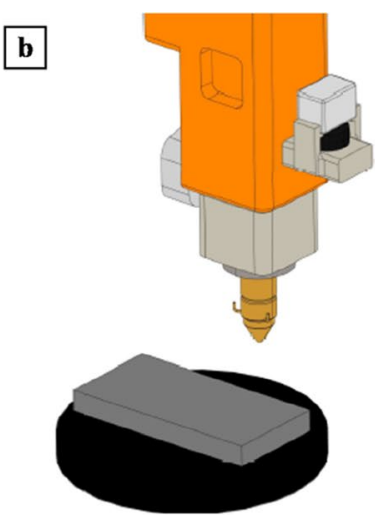

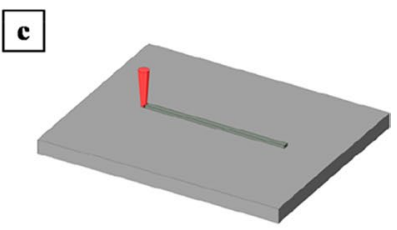


Table 2 DLMD process parameters

\begin{tabular}{lll}
\hline Process parameter & Value & Unit \\
\hline Laser power & 600 & $\mathrm{~W}$ \\
Laser spot diameter & 1.50 & $\mathrm{~mm}$ \\
Scanning speed & 500 & $\mathrm{~mm} / \mathrm{min}$ \\
Powder feed rate & 10 & $\mathrm{~g} / \mathrm{min}$ \\
Argon gas flow rate & 10 & $1 / \mathrm{min}$ \\
\hline
\end{tabular}

In Fig. 3, the design of the DLMD process model is shown. This schematic representation is also useful to highlight the interconnections inside the complex network of sub-units composing the model and the parameters analyzed by EA. The main sub-unit is the glove-box (cooled by the chiller for nozzle) inside of which the laser deposition process is carried out. The laser beam is generated by the laser source connected to two chiller systems (chiller for core and chiller for fiber). In parallel, the powder flow is regulated by the powder feeder. Ultimately, there is the suction system that purifies the post-deposition environment.

The inventory of the data required to implement the EA highlights the numerous key points of the DLMD system.
The main controlled parameters to be monitored were chosen in a first stage, such as the electrical energy consumptions and the temperature of the melt pool during the deposition. In the model, it is noted how the material flows (powder, gas, and water) travel through the several sub-units of the system, eventually changing their physical proprieties at each stage. However, at certain operational phases, the difficulty in monitoring temperatures and flow rates of in and out mass flows was recorded. This drawback shows how well, before carrying out the analysis, the thermodynamic modelling has been useful for the detection of the monitoring framework requirements. A network of sensors is necessary to compose a database with values of all the parameters needed for the analysis. It was also pointed out how seeking greater accuracy in the analysis inevitably leads to a consequent complexity of the monitoring framework, bringing to a possible inclusion of additional sensors in each sub-unit. Complexity grows further considering the sampling frequency, which becomes another important requirement to synchronize all parameters that could be detected by the sensing framework. Finally, it can be asserted that, once the objective of the analysis has been defined, modelling is fundamental to determine boundaries and limitations of the system under consideration.

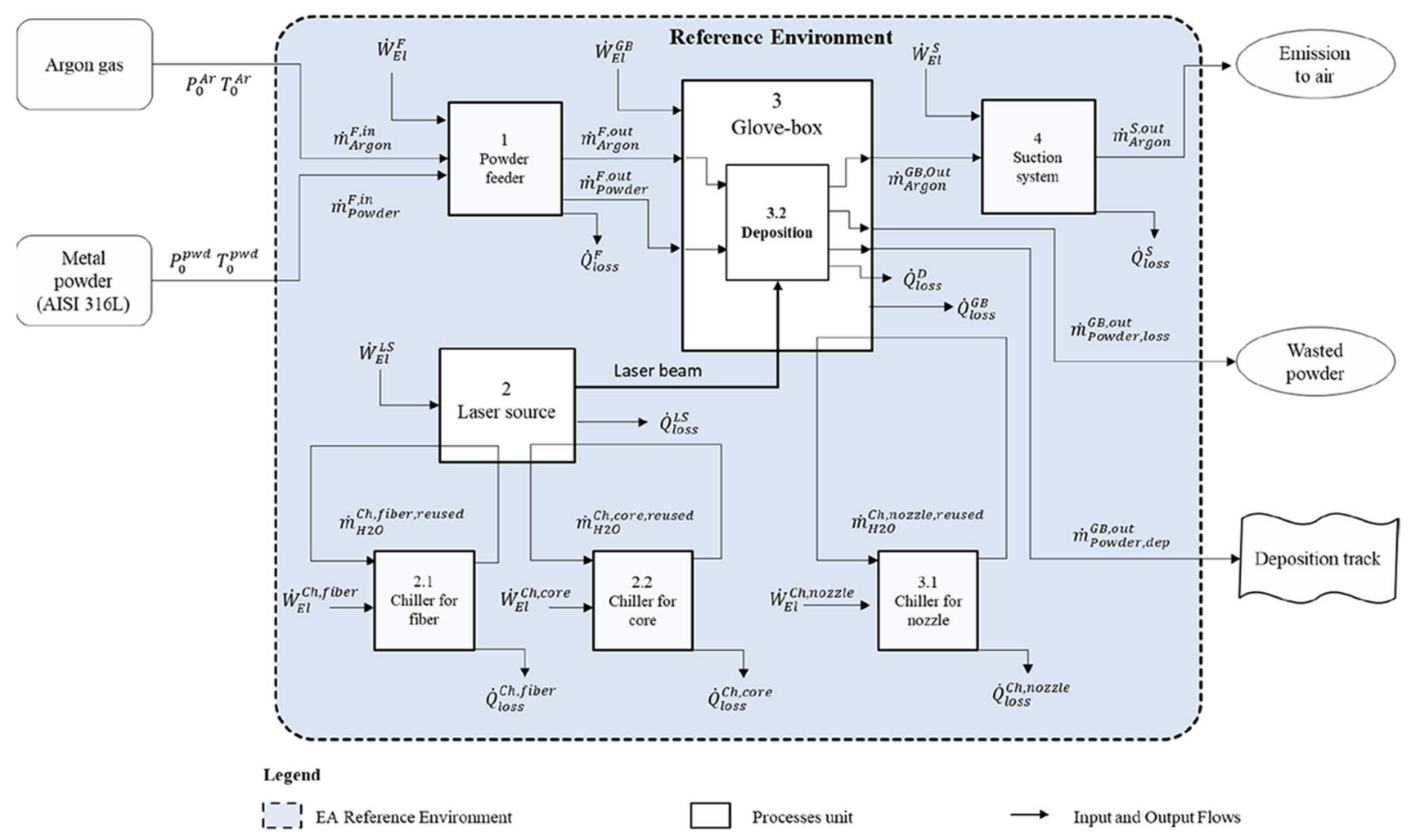

Fig. 3 DLMD thermodynamic model 


\subsection{Description of the monitoring framework of DLMD}

A monitoring system has been developed based on Raspberry Pi [62] and Python v. 3.8 [63] to meet the thermodynamic model requirements. The first is characterized by several advantages such as small dimensions, low cost, and high flexibility due to the large set of software and hardware tools available. The latter is a quite recent multiplatform interpreter widely used by the scientific community in realtime applications, robotics, deep learning, image processing, database server, and monitoring systems. In the last decade, it has climbed to the top of most used scientific software, thanks to its easy intuitive syntax and its flexibility. In this specific application, the Raspberry Pi 4 has been selected, showing the following specifications:

- Broadcom BCM2711, Quad core Cortex-A72 (ARM v8) 64-bit SoC at $1.5 \mathrm{GHz}$

- 2 GB, 4 GB, or 8 GB LPDDR4-3200 SDRAM (depending on the model)

- Gigabit Ethernet

This choice guarantees both hardware and software flexibility to perform the EA. The aim of the proposed monitoring framework is to include different sensing units such as energy meters, flow sensors, and thermal sensors in order to characterize the entire DLMD process. In particular, the measurement of the process temperature was carried out through an off-axis pyrometer (CellaTemp®, Keller ITS) attached to the deposition head, in order to capture the thermal parameters of the whole process. The emissivity value for AISI 316L stainless steel has been set based on previous works and literature data relating to laser processing [64].

A coaxial CCD camera (IDS ${ }^{\circledR}$, uEye RE) integrated into the deposition head was employed to monitor the melt pool throughout the deposition process. With a maximum frame rate of $40 \mathrm{~Hz}$, it is useful to verify the consistency of the process and detect the size of the treated area.

A set of energy meters (Siemens Sentron PAC 3200) were employed for electrical energy measurements. The energy meter had more of 200 parameters as float numbers. The acquired variables are active power [kW], reactive power [kVAr], active energy [kWh], reactive energy [kVArh], and voltage and current harmonics. The measuring accuracy of actual power is in the order of $0.5 \%$ [65].

The communication performances of the monitoring system have been tested with the Siemens Sentron PAC 3200 energy meter to evaluate the maximum acquisition rate. As a result of a preliminary test, the monitoring system was capable to acquire from a Modbus TCP device an amount of 100 word registers at $149 \mathrm{~Hz}$. This result was due to an appropriate acquisition strategy. In order to speed up the acquisition process, firstly, the Python script continuously read data on the device port 502, and later, data were elaborated and stored in a database. A schematic draw of the system architecture is shown in Fig. 4.

In addition to the aforementioned main sensors, the monitoring framework made use of several sensors embedded within each process unit. These were useful for the purposes of EA, allowing monitoring of secondary parameters such as temperatures and water flows in chiller systems. These parameters had smaller variation regimes than the main parameters, thus being considered a constant throughout the carried analysis. Although these have a marginal impact on the overall assessment, these are essential for determining the efficiency of each process unit.

Finally, the greatest difficulties from the measurement point of view were found in the real-time evaluation of the powder flow during the deposition process. This parameter is fundamental for the quality and the sustainability assessment of the laser deposition process because it strongly impacts on the deposited track. In the literature, the real-time measurement of this parameter remains an open challenge [66] also because there are few commercial devices capable of measuring it. As no suitable sensor was available, the powder flow assessment was carried out by means of a preliminary series of flow tests. These tests allowed the quantitative estimation of the powder mass flow rate, which was kept constant throughout the deposition process. The main variables of the EA and the related sensing units used to measure them are summarized in Table 3.

\subsection{Electrical energy and temperature acquisition test}

Electrical energy and power acquisition tests were performed by the Siemens Sentron PAC 3200, connected to each sub-unit of the prototype DLMD system. Figure 5 shows input and output power of the laser source during a testing deposition cycle of $2.4 \mathrm{~s}$ at a constant power for the laser output of $600 \mathrm{~W}$. The acquisition frequency of the DAQ system was $40 \mathrm{~Hz}$.

The energy meter update frequency is about $4 \mathrm{~Hz}$. Since the acquisition update frequency of the device is 10 times lower than the frequency of the DAQ system, the plot has a typical stepped shape. The input power reached a steady value after about $2 \mathrm{~s}$, since the laser source consists of an energy pumping mechanism that maintains the active material in an excited state in standby condition. This allowed a gradually increase in input power to provide a constant output power. The laser deposition is a process that usually operates in conduction mode requiring lower powers than laser welding, in which very high energy densities are necessary to work in keyhole mode and instantly vaporize the material [67]. The 4-kW laser source mounted in the 
Fig. 4 Sensing units and monitoring system architecture

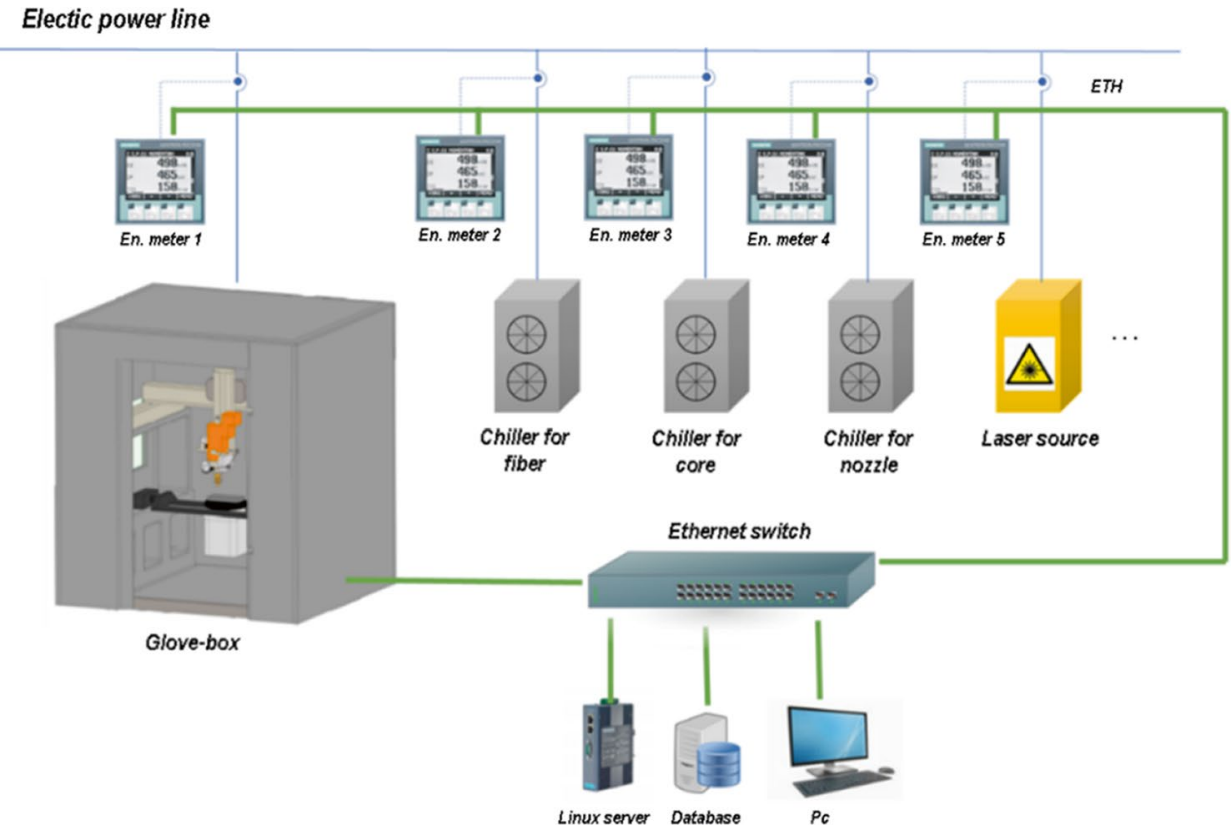

Table 3 Measured parameters of DLMD process

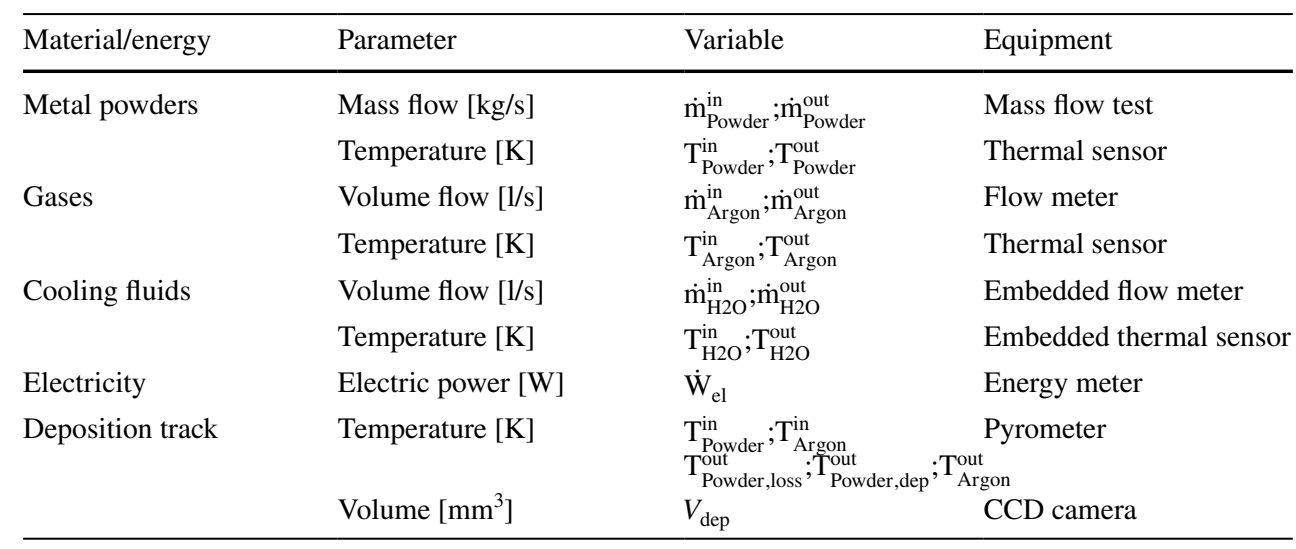

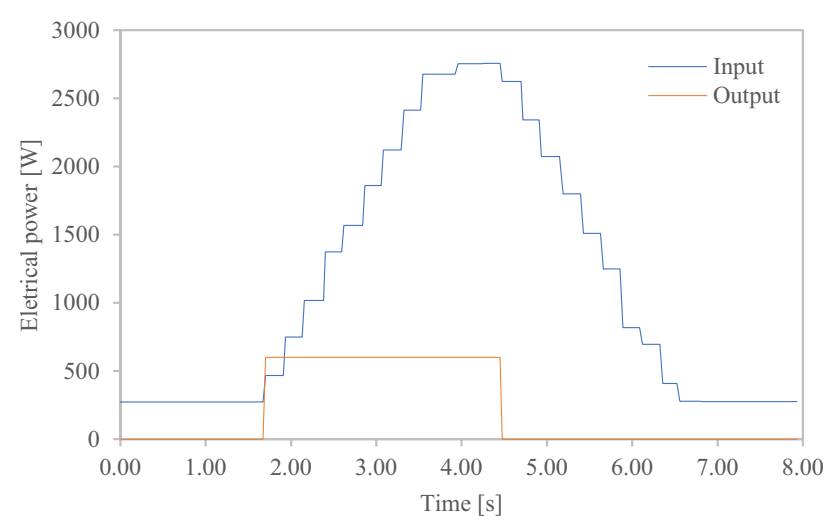

Fig. 5 Laser beam input and output power during deposition cycle
DLMD system is then used with powers close to the lowest limit available for stable processing, equal to $10 \%$ of the nominal power.

On the other hand, Fig. 6a shows the input power of the chiller system for the laser source. The plot shows a basic power consumption of the machine of $4800 \mathrm{~W}$ with load cycles reaching peaks of $6800 \mathrm{~W}$. The trend and frequency of the peaks are strictly related to the laser source activity and the output laser power required by the processing. Figure $6 \mathrm{~b}$ shows the input power of the chiller system for the fiber. The device can be outlined as a simple heat exchanger without any input power control system. In fact, this power is not affected by working cycles of the source and stands at a constant value of $450 \mathrm{~W}$. Figure $6 \mathrm{c}$ plots the trend of the incoming electrical power for the chiller system for the nozzle: similar to the core chiller, this device has load cycles influenced by the deposition process and mainly by the thermal energy reflected by the melt pool, which overheats the 
Fig. 6 a Chiller for core, $\mathbf{b}$ chiller for fiber, c chiller for nozzle, and $\mathbf{d}$ glove-box input electrical power during deposition cycles
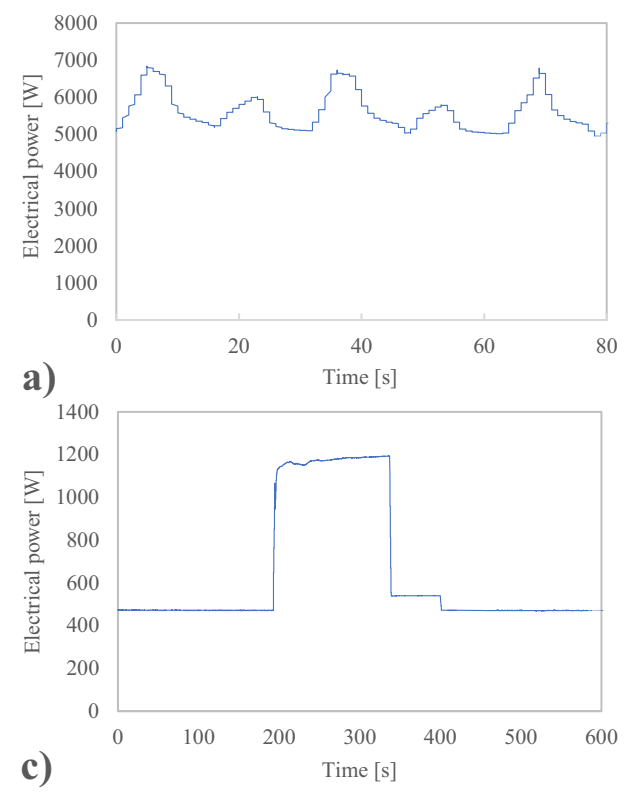
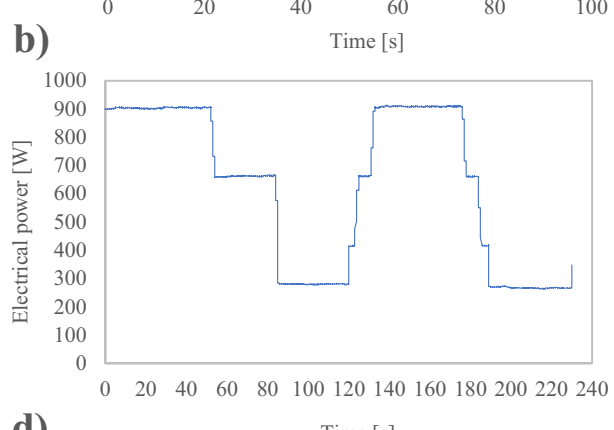

nozzle and the optics. During process downtime, the chiller handles a limited temperature variation of the deposition head, which allows the system to be kept on standby for a long time. This is less clear on the core chiller because during the standby of the laser source, the pumping mechanism still produces a certain amount of waste heat which is managed by the chiller.

In Fig. 6d, the consumptions of the glove-box are plotted. This apparatus is an agglomeration of various devices useful for DLMD operations, such as a PC, a laser head handling system, and monitoring systems. The trend over time of the electrical input power is irregular because it is influenced by the activity sequences of components during the deposition process. However, there is a maximum input power value that reaches $900 \mathrm{~W}$ and a minimum value that is around $300 \mathrm{~W}$.

The power values recorded by means of the energy meter during preliminary tests on components constituting the DLMD system and employed in the EA are summarized in Table 4. Maximum and minimum values have been listed because not all components were active during the deposition process. For example, the suction system is activated only at the end of the processing cycle, to clean the glovebox environment from argon and the fraction of floating wasted metal particles. In fact, the system is coupled with a gravimetric dispenser which doses the calcium carbonate to reduce the risk of explosions deriving from processing of fine metal powder.

The EA is a method mainly based on thermodynamics that evaluates the energetic behavior of manufacturing systems by comparing them to the Carnot cycle. In order to obtain energy and exergy values of the system, it is essential to record the main thermal parameters of the material flows.
Table 4 Electrical power distribution

\begin{tabular}{lllll}
\hline Device & Parameter & Unit & Max value & Min value \\
\hline Powder feeder & $\dot{\mathrm{W}}_{E l, i n}^{F,}$ & $\mathrm{~W}$ & 240 & 240 \\
Laser source & $\dot{\mathrm{W}}_{E l, \text { in }}^{L S}$ & $\mathrm{~W}$ & 2820 & 400 \\
Chiller for fiber & $\dot{\mathrm{W}}_{E l, \text { in }}^{\text {Ch, }}$ & $\mathrm{W}$ & 450 & 450 \\
Chiller for core & $\dot{\mathrm{W}}_{E, \text { lin }}^{\text {Ch. }}$ & $\mathrm{W}$ & 6800 & 4800 \\
Glove-box & $\dot{\mathrm{W}}_{E l, \text { in }}^{G B}$ & $\mathrm{~W}$ & 900 & 300 \\
Chiller for nozzle & $\dot{\mathrm{W}}_{E, \text {,in }}^{\text {Chozzle }}$ & $\mathrm{W}$ & 1200 & 500 \\
Suction system & $\dot{\mathrm{W}}_{E l, \text { in }}^{S}$ & $\mathrm{~W}$ & 1500 & 300 \\
\hline
\end{tabular}

Table 5 Material properties

\begin{tabular}{llllll}
\hline State functions & Symbol & Unit & Metal powder & Argon & Water \\
\hline $\begin{array}{l}\text { Dead state tem- } \\
\text { perature }\end{array}$ & $\mathrm{T}_{0}$ & $\mathrm{~K}$ & 298.15 & 293.15 & 293.15 \\
$\begin{array}{l}\text { Dead state pres- } \\
\text { sure }\end{array}$ & $\mathrm{P}_{0}$ & $\mathrm{~atm}$ & 0.987 & 4.935 & 0.987 \\
$\begin{array}{l}\text { Specific heat } \\
\text { pear }\end{array}$ & $\mathrm{c}_{\mathrm{p}}$ & $\mathrm{J} / \mathrm{kg} \mathrm{K}$ & 500 & 520 & 4186 \\
\hline
\end{tabular}

Table 5 lists temperature, pressure, and specific heat values for argon, AISI 316L metal powder, and water for chiller systems. The dead state corresponds to the thermal equilibrium between the system and its surroundings.

Therefore, it is essential for EA to evaluate the temperature variations during processing. These data were obtained for each component of the system in different ways: directly, through the usage of primary monitoring systems such as pyrometers or through monitoring systems embedded into the sub-units, and indirectly from literature, data sheets, and 
simulations. Figure 7 shows the plot of the maximum temperature of the single-track deposition process measured by the pyrometer.

\subsection{Exergetic analysis: results and discussion}

The purpose of the proposed analysis is to prove the effectiveness of the monitoring system designed by applying the thermodynamic model. The current equipment and framework provided upstream and downstream process flow data and information for validation (or partial model simulation) of the EA.

By considering negligible leakage in the chiller systems during the process, and that the water flow inside the chillers runs cyclically, it is possible to assume that the mass balance will always be equal to zero. Therefore, the mass balance of argon and AISI $316 \mathrm{~L}$ powder only was considered.

Concerning the graph in Fig. 8a and b, the argon flow was considered to be entirely necessary for the production of the

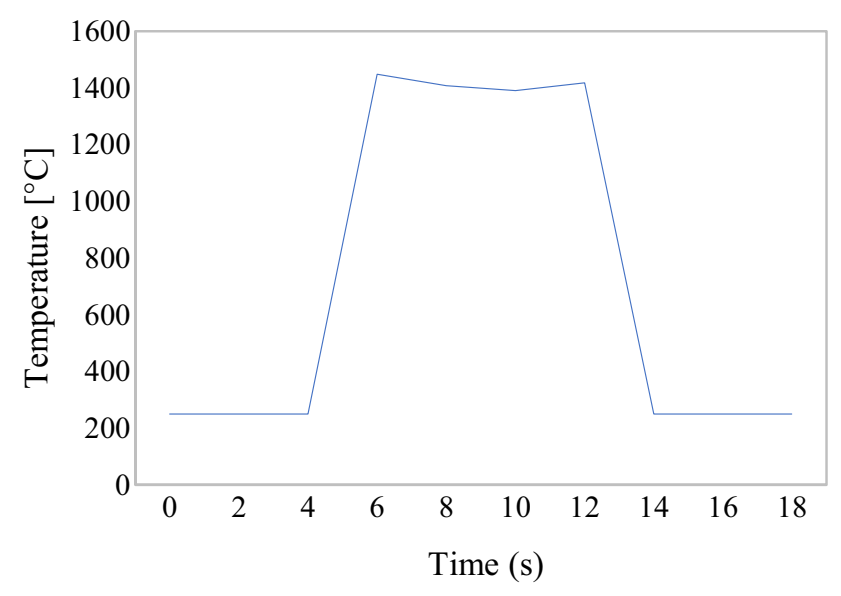

Fig. 7 Temperatures measured by the pyrometer during deposition process deposition clad, and for this reason, although it is not materially part of the final component, its output quantity was not considered a loss. On the contrary, for a coaxial nozzle, the powder was considered $60 \%$ useful for cladding according to the deposition efficiency calculation provided by [68] and $40 \%$ was considered wasted inside the glove-box and was therefore considered lost mass.

In order to simplify the process analysis, some assumptions have been made: (a) the system operates under steady state conditions, (b) the pressure drops related to all losses along the system are negligible, and (c) each processing unit is insulated, and thus the heat transfer to the environment is negligible. The graphs in Fig. 8 were obtained through Eq. (1) introduced in Section 2.3, while the graphs in Fig. 9 were obtained via the Eqs. (2) and (3), respectively, by integrating every single equation over the deposition cycle time.

Any activity or process that involves a work necessitates the use of energy, which manifests itself primarily in two types: work and heat. In general, for each energy transformation, its performance can be calculated as the percentage of the input energy that is converted into the desired final type. In the work, in order to compare the efficiency of the process based on the energy and the exergy analysis, two categories of allocations for the output energy have been defined. Taking as a reference the differentiation between exergy out $\left(\mathrm{Ex}_{\mathrm{out}}\right)$ and exergy loss $\left(\mathrm{Ex}_{\mathrm{loss}}\right)$ introduced in Eq. (3), the amount of energy useful for the production of the final product $\left(\mathrm{En}_{\text {out,dep }}\right)$ and the amount of energy unnecessary for manufacturing the component and thus destinated to wasted materials and emissions $\left(\mathrm{En}_{\text {out,waste }}\right)$ have been defined. Figure 9 shows that nearly $70 \%$ of the incoming energy (see Fig. 9a) was converted to heat, which was dissipated in the environment during the process and was useless for the production of the deposition track and almost $92 \%$ of the incoming exergy (see Fig. 9b) was lost as well. The input fraction was determined by the electrical and material flows, which contribute to the balance through enthalpy, depending
Fig. 8 Mass balances of $\mathbf{a}$ argon and $\mathbf{b}$ AISI $316 \mathrm{~L}$ powder
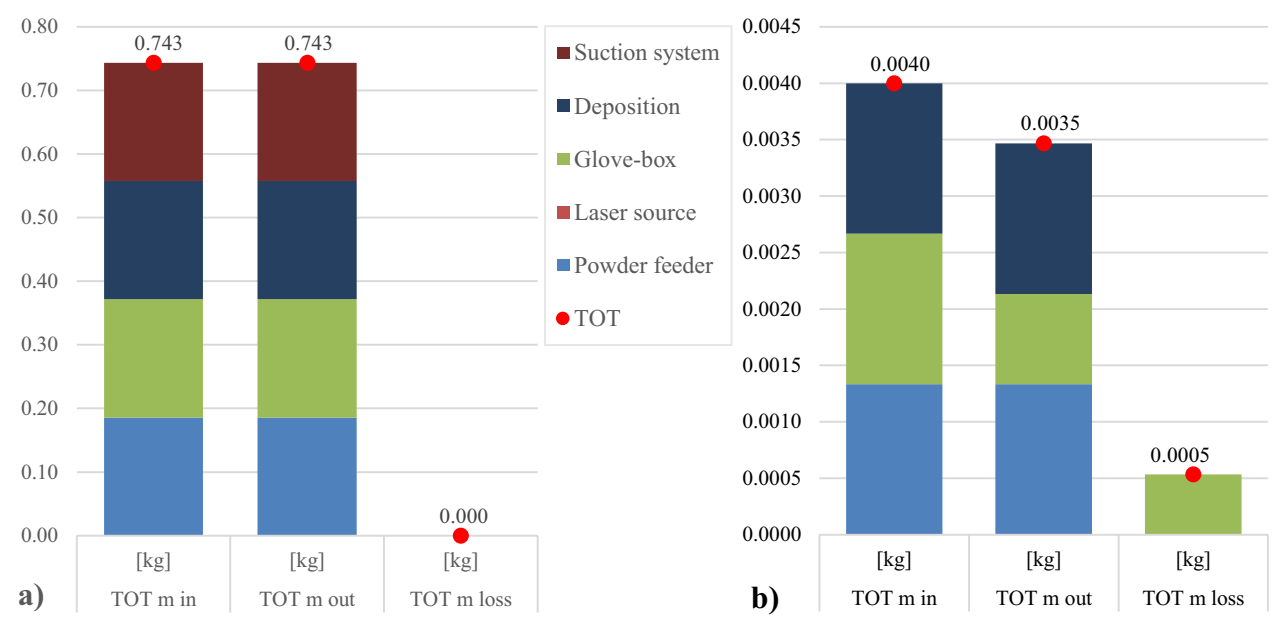
Fig. 9 Energy (a) and exergy (b) balances

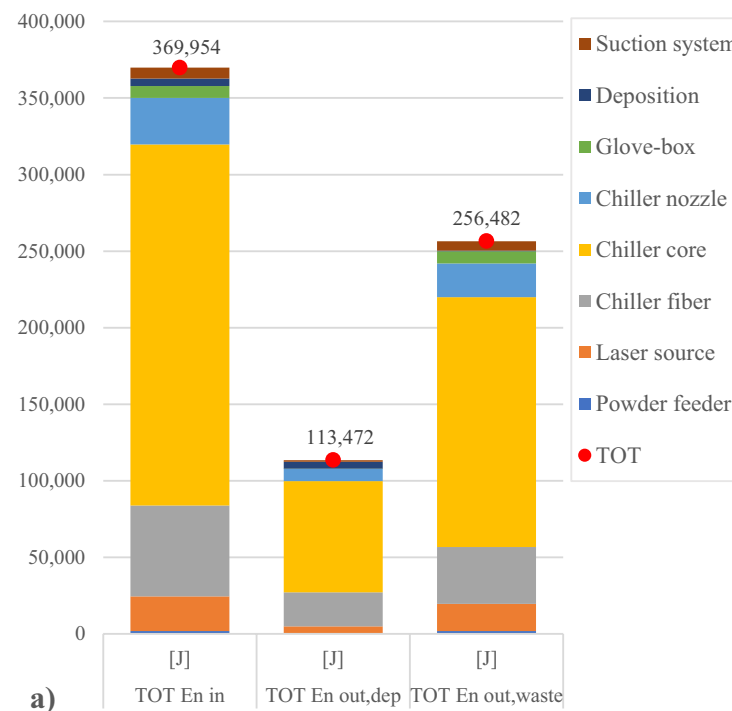

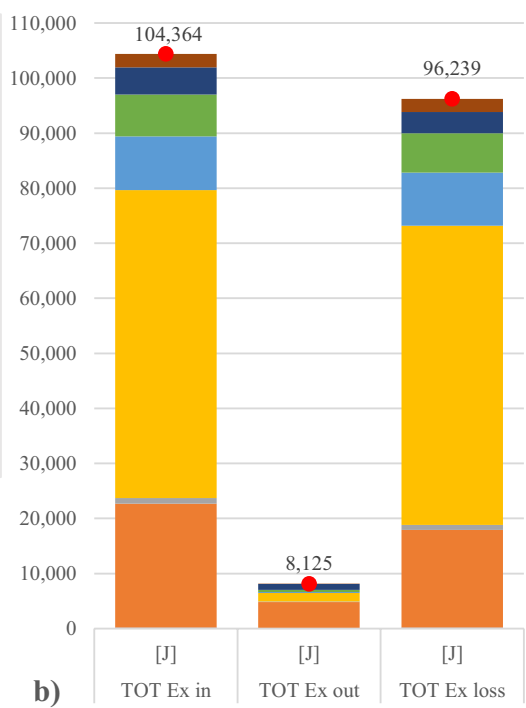

on both the specific heat and the temperature difference between the dead state and the incoming temperature (see Eq. (5) in Section 2.3). The lost fraction corresponds to all the dispersed energy, which was not useful for the deposition process. As can be seen from the graphs, the three chiller systems appear to be the most energy-demanding units. The situation is slightly different regarding exergies, as the most active processing unit appears to be the chiller for core, followed by the laser source.

Figure 10 shows the exergetic efficiency of each processing unit. The substantial difference between net use and general efficiency lies in the fact that the former considers only the exergies useful for the implementation of the deposition process, whereas in the latter, all incoming and outgoing exergies are considered expressed in Eqs. (8) and (9) in Section 2.3. Figure 10 also shows the overall efficiencies of the entire process.

The laser source has an efficiency of about $21 \%$, consistent with the literature on solid state laser sources. As could be expected, the efficiencies of the chillers turn out to be low, as these absorb more electrical power than the power needed to produce the useful work for the process. The devices are oversized related to the process under consideration, as the system is multipurpose and must also cover the needs arising from different processes such as laser welding.

On the right, Fig. 10 shows the exergetic efficiency of the actual deposition process which takes place inside the glovebox, but deserves a specific study, as at this stage, the temperature differences of the materials may change abruptly. The value represents the energy (related to the laser beam) provided to the deposition point in order to create the track, but also wasted to heat up other elements involved in this phase of the process, i.e., the powder dispersed in the glovebox, the substrate, and the argon that is dropped out by the suction system. Temperatures were measured by means of the pyrometer but a reference was made to [69] to approximate the overheating of the substrate and to quantify the energy lost during the deposition.

Exergetic efficiencies are more complex than energy efficiencies because they consider the useful work generated during the process and related to the maximum work of the Carnot cycle. By controlling energy yields, these are higher and in line with the usual values: for example, the energy efficiency of the chiller systems ranges from 25 to $40 \%$.

Analyzing the energy balance, the larger fraction of the consumed energy can be allocated to the generation of the
Fig. 10 Process units, deposition phase, and overall process exergetic efficiencies

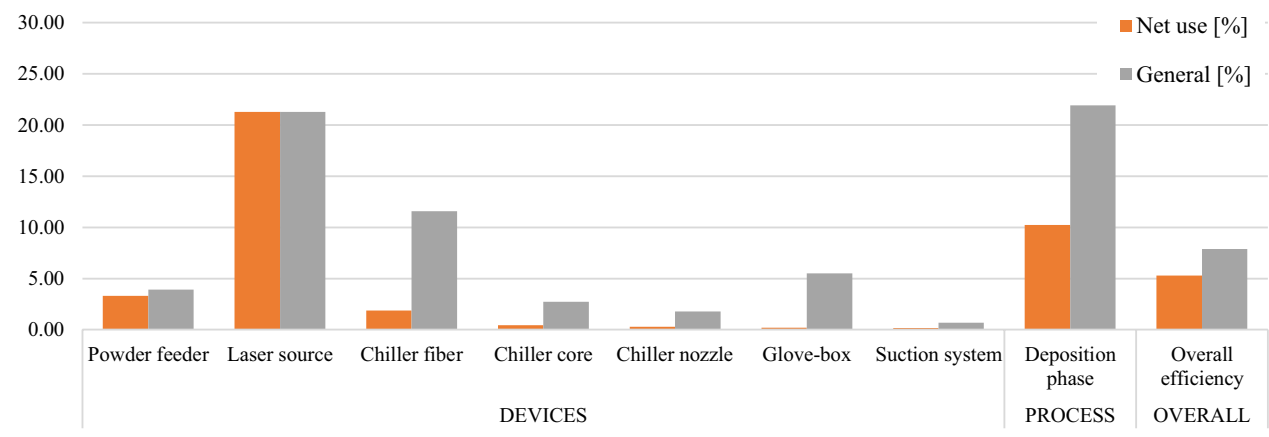


laser beam. This result is consistent with other works in the literature [70] that describe the DLMD process as the most energetic AM technology currently existing (considering an average energy demand of 7,779 MJ per every kg of deposited mass).

Another food for thought regarding the obtained results is the lack of bibliographical studies on the environmental impact on DLMD systems that considers all components of the system acting in the process. For example, there is an almost total lack of studies on the impact of chillers on the efficiency of laser beam generation and on the overall process.

Works carried out through exergetic modelling have the advantage of assessing both the general impact of the laser deposition process and the decomposition of the system into processing units so as to be capable to identify the energy and exergetic contribution for each of them. In addition, it was possible to define the efficiency of the individual devices to plan for improvement on the most energy-intensive processing units and therefore to prioritize the components that need to be modified.

\section{Conclusions and further developments}

In view of the aforementioned discussion, an appropriate system was developed to store, collect, and analyze a comprehensive set of parameters. The novel system framework, applied for the first time in the additive manufacturing field, has proved to be effective in carrying out an accurate quality and sustainability assessment of the DLMD process under analysis. The main outcomes obtained from the exergetic analysis were the following:

- The energy and exergy balance showed almost $70 \%$ of the energy and $92 \%$ of the exergy incoming to the system were lost during the process.

- Chiller systems were the most energy-intensive sub-units of the system, requiring $88 \%$ of the total incoming energy and $64 \%$ of the incoming exergy.

- The deposition process reported a very low exergy efficiency (about $10 \%$ of net and $22 \%$ of general), while at system level, the efficiency of the DLMD system fell to $5 \%$ of net and $8 \%$ of general efficiency.

The thermodynamic process modelling, as well as the analysis itself, has made possible to identify the open issues and criticalities related to the monitoring and control system designed in this work in view to a further real-time monitoring and control procedure of the DLMD process: (a) the problem of synchronization of sampling frequencies will be studied in depth, as well as the possibility of integrating data from new devices into a single database; (b) the analysis of complex deposition strategies, focusing on the idle time between contiguous subphases throughout the process to detect variations in energy/exergy loss for each sub-unit; (c) the analysis could even focus on environmental sustainability through the implementation of a full EA-LCA model. Given the benefits in coupling EA with LCA for this kind of process analysis, the thermodynamic model to be implemented may be much more effective if coupled with the LCA: at first, this can provide more objective-oriented outcomes of the assessment; on a second instance, this will become a helpful tool for decision-making policies aimed at developing evolutionary solutions, thus enabling the process to automatically prevent any possible failure. The implementation of a comprehensive EA-LCA approach, which relates the environmental impacts to the quality of components made through DLMD process, will be the focus of the next work. Moreover, the full EA-LCA model with a proper sensing and monitoring system may enable any practitioner to restructure both process hardware and software to smart I4.0 standards almost in real time, thus improving the cost-efficiency.

Funding Open access funding provided by Politecnico di Bari within the CRUI-CARE Agreement. This paper has been partially funded by the Italian Ministry of Education, University and Research, under the project \# ARS01_00806 "Innovative Solutions for Quality and Sustainability of Advanced Manufacturing Processes" (grant PNR 2015-2020, di cui al D.D. del 13 luglio 2017 n. 1735) and under the Programme "Department of Excellence" Legge 232/2016 (grant no. CUP-D94I18000260001)".

Data availability Not applicable.

\section{Declarations}

Ethics approval and consent to participate Not applicable.

Consent for publication All authors consent to the publication of the manuscript in this journal.

Conflict of interest The authors declare no competing interests.

Open Access This article is licensed under a Creative Commons Attribution 4.0 International License, which permits use, sharing, adaptation, distribution and reproduction in any medium or format, as long as you give appropriate credit to the original author(s) and the source, provide a link to the Creative Commons licence, and indicate if changes were made. The images or other third party material in this article are included in the article's Creative Commons licence, unless indicated otherwise in a credit line to the material. If material is not included in the article's Creative Commons licence and your intended use is not permitted by statutory regulation or exceeds the permitted use, you will need to obtain permission directly from the copyright holder. To view a copy of this licence, visit http://creativecommons.org/licenses/by/4.0/. 


\section{References}

1. Tay S, Te Chuan L, Aziati A, Ahmad ANA (2018) An overview of Industry 4.0: Definition, components, and government initiatives. Journal of Advanced Research in Dynamical and Control Systems $10: 14$

2. Schumacher A, Nemeth T, Sihn W (2019) Roadmapping towards industrial digitalization based on an Industry 4.0 maturity model for manufacturing enterprises. Procedia CIRP 79:409-14. https:// doi.org/10.1016/j.procir.2019.02.110

3. Ruppert T, Jaskó S, Holczinger T, Abonyi J (2018) Enabling technologies for Operator 4.0: a survey. Applied Sciences 8:1650. https://doi.org/10.3390/app8091650

4. Chiarello F, Trivelli L, Bonaccorsi A, Fantoni G (2018) Extracting and mapping industry 4.0 technologies using wikipedia. Computers in Industry 100:244-57. https://doi.org/10.1016/j.compind.2018.04.006

5. Galantucci LM, Guerra MG, Dassisti M, Lavecchia F (2019) Additive manufacturing: new trends in the 4th Industrial Revolution. In: Monostori L, Majstorovic VD, Hu SJ, Djurdjanovic $\mathrm{D}$ (eds) Proceedings of the 4th International Conference on the Industry 4.0 Model for Advanced Manufacturing. Springer International Publishing, Cham, pp 153-69. https://doi.org/10.1007/ 978-3-030-18180-2_12

6. Schütze A, Helwig N, Schneider T (2018) Sensors 4.0 - smart sensors and measurement technology enable Industry 4.0. J Sens Sens Syst 7:359-71. https://doi.org/10.5194/jsss-7-359-2018

7. Schaudel D (2015) Sensor 4.0 für Industrie 4.0. Hotel Elbflorenz, Dresden, p 5. https://doi.org/10.5162/12dss2015/4.1

8. Ford S, Despeisse M (2016) Additive manufacturing and sustainability: an exploratory study of the advantages and challenges. J Clean Prod 137:1573-1587. https://doi.org/10.1016/j.jclepro.2016.04.150

9. Faludi J, Bayley C, Bhogal S, Iribarne M (2015) Comparing environmental impacts of additive manufacturing vs traditional machining via life-cycle assessment. Rapid Prototyp J 21:14-33. https://doi.org/10.1108/RPJ-07-2013-0067

10. Eslami Y, Lezoche M, Panetto H, Dassisti M (2020) On analysing sustainability assessment in manufacturing organisations: a survey. International Journal of Production Research 59:4108-39. https://doi.org/10.1080/00207543.2020.1755066

11. Taddese G, Durieux S, Duc E (2020) Sustainability performance indicators for additive manufacturing: a literature review based on product life cycle studies. Int J Adv Manuf Technol 107:31093134. https://doi.org/10.1007/s00170-020-05249-2

12. Ahn D-G (2016) Direct metal additive manufacturing processes and their sustainable applications for green technology: a review. Int J of Precis Eng and Manuf-Green Tech 3:381-395. https://doi. org/10.1007/s40684-016-0048-9

13. Cornelissen RL (1997) Thermodynamics and sustainable development; the use of exergy analysis and the reduction of irreversibility

14. European Commission (2016) Joint Research Centre. Life cycle assessment for the impact assessment of policies. Publications Office, LU

15 Selicati V, Cardinale N (2020) Benchmarking sustainability on an industrial case within Industry 4.0 Paradigm: advantages of involving exergetic analysis in life cycle thinking. TI-IJES 64:244-50. https://doi.org/10.18280/ti-ijes.642-418

16. Montero Jimenez JJ, Schwartz S, Vingerhoeds R, Grabot B, Salaün M (2020) Towards multi-model approaches to predictive maintenance: a systematic literature survey on diagnostics and prognostics. J Manuf Syst 56:539-557. https://doi.org/10.1016/j.jmsy.2020.07.008

17. Gupta K (ed) (2017) Advanced Manufacturing Technologies. Springer International Publishing, Cham

18. Singla AK, Banerjee M, Sharma A, Singh J, Bansal A, Gupta MK et al (2021) Selective laser melting of Ti6Al4V alloy: process parameters, defects and post-treatments. J Manuf Process 64:161-187. https://doi.org/10.1016/j.jmapro.2021.01.009
19. Zobler M, Mantwill E (2018) Cooling solutions for laser applications: why a tailor-made chiller supports the optimal performance of the laser and reduces energy costs. Laser Tech J 15:50-55. https://doi.org/10.1002/latj.201800020

20. DebRoy T, Wei HL, Zuback JS, Mukherjee T, Elmer JW, Milewski JO et al (2018) Additive manufacturing of metallic components - process, structure and properties. Prog Mater Sci 92:112-224. https://doi.org/10.1016/j.pmatsci.2017.10.001

21. Machado CG, Despeisse M, Winroth M, da Silva EHDR (2019) Additive manufacturing from the sustainability perspective: proposal for a self-assessment tool. Procedia CIRP 81:482-487. https://doi.org/10.1016/j.procir.2019.03.123

22. Výtisk J, Kočí V, Honus S, Vrtek M (2019) Current options in the life cycle assessment of additive manufacturing products. Open Engineering 9:674-682. https://doi.org/10.1515/eng-2019-0073

23 Wrisberg N, Udo de Haes HA, Triebswetter U, Eder P, Clift R (eds) (2002) Analytical tools for environmental design and management in a systems perspective, vol 10. Springer, Netherlands, Dordrecht. https://doi.org/10.1007/978-94-010-0456-5

24. Brunner PH, Rechberger H (2004) Practical handbook of material flow analysis. CRC/Lewis, Boca Raton

25. Frischknecht R, Jungbluth N, Althaus H-J, Bauer C, Doka G, Dones R, Hischier R, Hellweg S, Humbert S, Köllner T, Loerincik Y, Margni M, Nemecek T (2007) Implementation of life cycle impact assessment methods. ecoinvent report No. 3, v2.0. Swiss Centre for Life Cycle Inventories, Dübendorf 20(3):1-139

26. UNI EN ISO 14040:2006 2006. http://store.uni.com/catalogo/index. php/uni-en-iso-14040-2006.html (accessed February 5, 2019)

27. Chevalier J (1999) Elaboration of a protocol for processes life cycle assessment. Ph.D. Dissertation. Lyon, France: Institut National des Sciences Appliquées. Ph.D. Dissertation. Lyon, France: Institut National des Sciences Appliquées

28. Paris H, Mokhtarian H, Coatanéa E, Museau M, Ituarte IF (2016) Comparative environmental impacts of additive and subtractive manufacturing technologies. CIRP Ann 65:29-32. https://doi.org/ 10.1016/j.cirp.2016.04.036

29. Le VT, Paris H (2018) A life cycle assessment-based approach for evaluating the influence of total build height and batch size on the environmental performance of electron beam melting. Int J Adv Manuf Technol 98:275-288. https://doi.org/10.1007/ s00170-018-2264-7

30. Jiang J, Ma Y (2020) Path planning strategies to optimize accuracy, quality, build time and material use in additive manufacturing: a review. Micromachines 11:633. https://doi.org/10.3390/mi11070633

31. Bourhis FL, Kerbrat O, Hascoet J-Y, Mognol P (2013) Sustainable manufacturing: evaluation and modeling of environmental impacts in additive manufacturing. Int J Adv Manuf Technol 69:1927-1939. https://doi.org/10.1007/s00170-013-5151-2

32. Arrizubieta JI, Ukar O, Ostolaza M, Mugica A (2020) Study of the environmental implications of using metal powder in additive manufacturing and its handling. Metals 10:261. https://doi.org/10. 3390/met10020261

33. Meteyer S, Xu X, Perry N, Zhao YF (2014) Energy and Material Flow Analysis of Binder-jetting Additive Manufacturing Processes. Procedia CIRP 15:19-25. https://doi.org/10.1016/j.procir. 2014.06.030

34. Rant Z (1956) Exergie, ein neues Wort für "technische Arbeitsfähigkeit.” Forschung Im Ingenieurwesen 22:36-7. https://doi.org/ 10.1007/BF02592661

35. Li B, Cao H, Liu H, Zeng D, Chen E (2019) Exergy efficiency optimization model of motorized spindle system for high-speed dry hobbing. Int J Adv Manuf Technol 104:2657-2668. https:// doi.org/10.1007/s00170-019-04134-x

36. Renaldi, Kellens K, Dewulf W, Duflou JR (2011) Exergy Efficiency Definitions for Manufacturing Processes. In: Hesselbach J, Herrmann C (eds). Glocalized Solutions for Sustainability in 
Manufacturing, Berlin, Heidelberg: Springer, Berlin, pp 329-34. https://doi.org/10.1007/978-3-642-19692-8_57

37. Selicati V, Cardinale N, Dassisti M (2021) The interoperability of exergy and Life Cycle Thinking in assessing manufacturing sustainability: A review of hybrid approaches. J Clean Prod 286:124932. https://doi.org/10.1016/j.jclepro.2020.124932

38. Jiang Q, Liu Z, Li T, Cong W, Zhang H-C (2019) Emergy-based life-cycle assessment (Em-LCA) for sustainability assessment: a case study of laser additive manufacturing versus $\mathrm{CNC}$ machining. Int J Adv Manuf Technol 102:4109-4120. https://doi.org/10.1007/ s00170-019-03486-8

39. Nagarajan HPN, Haapala KR (2018) Characterizing the influence of resource-energy-exergy factors on the environmental performance of additive manufacturing systems. J Manuf Syst 48:87-96. https://doi.org/10.1016/j.jmsy.2018.06.005

40. Le VT, Paris H, Mandil G (2017) Environmental impact assessment of an innovative strategy based on an additive and subtractive manufacturing combination. J Clean Prod 164:508-523. https://doi.org/10.1016/j.jclepro.2017.06.204

41. Szargut J, Morris DR, Steward FR (1987) Exergy analysis of thermal, chemical, and metallurgical processes. United States: Hemisphere Publishing, New York, NY

42. Bakshi BR, Gutowski T, Sekulic D (2011) Thermodynamics and the destruction of resources. Cambridge University Press

43. Terzi R (2018) Application of Exergy Analysis to Energy Systems, Application of Exergy, Tolga Taner, IntechOpen. https://doi.org/ 10.5772/intechopen.74433. https://www.intechopen.com/chapters/ 60220

44. Paul R, Anand S (2012) Process energy analysis and optimization in selective laser sintering. J Manufac Syst 31:429-37. https://doi. org/10.1016/j.jmsy.2012.07.004

45. Kamps T, Lutter-Guenther M, Seidel C, Gutowski T, Reinhart G (2018) Cost- and energy-efficient manufacture of gears by laser beam melting. CIRP J Manuf Sci Technol 21:47-60. https://doi. org/10.1016/j.cirpj.2018.01.002

46. Bourell DL, Leu MC, Rosen DW (2009) Roadmap for additive manufacturing: identifying the future of freeform processing. Solid Freeform Fabr. Austin, TX: University of Texas Press

47. Everton SK, Hirsch M, Stravroulakis P, Leach RK, Clare AT (2016) Review of in-situ process monitoring and in-situ metrology for metal additive manufacturing. Mater Des 95:431-445. https://doi.org/10.1016/j.matdes.2016.01.099

48. Kledwig C, Perfahl H, Reisacher M, Brückner F, Bliedtner J, Leyens C (2019) Analysis of melt pool characteristics and process parameters using a coaxial monitoring system during directed energy deposition in additive manufacturing. Materials 12:308. https://doi.org/10.3390/ma12020308

49. Vandone A, Baraldo S, Valente A, Mazzucato F (2019) Visionbased melt pool monitoring system setup for additive manufacturing. Procedia CIRP 81:747-752. https://doi.org/10.1016/j.procir. 2019.03.188

50. Heralić A, Christiansson A-K, Lennartson B (2012) Height control of laser metal-wire deposition based on iterative learning control and 3D scanning. Opt Lasers Eng 50:1230-1241. https://doi. org/10.1016/j.optlaseng.2012.03.016

51. Donadello S, Motta M, Demir AG, Previtali B (2019) Monitoring of laser metal deposition height by means of coaxial laser triangulation. Opt Lasers Eng 112:136-144

52. Purtonen T, Kalliosaari A, Salminen A (2014) Monitoring and adaptive control of laser processes. Phys Procedia 56:1218-1231. https://doi.org/10.1016/j.phpro.2014.08.038

53. Chabot A, Rauch M, Hascoët J-Y (2019) Towards a multi-sensor monitoring methodology for AM metallic processes. Weld World 63:759-769. https://doi.org/10.1007/s40194-019-00705-4

54. He K, Hong H, Tang R, Wei J (2020) Analysis of multi-objective optimization of machining allowance distribution and parameters for energy saving strategy. Sustainability 12:638. https://doi.org/ $10.3390 /$ su 12020638

55. Pringle AM, Oberloier S, Petsiuk AL, Sanders PG, Pearce JM (2020) Open source arc analyzer: Multi-sensor monitoring of wire arc additive manufacturing. HardwareX 8:e00137. https://doi.org/ 10.1016/j.ohx.2020.e00137

56. Mudaliar MD, Sivakumar N (2020) IoT based real time energy monitoring system using Raspberry Pi. Internet of Things 12:100292. https://doi.org/10.1016/j.iot.2020.100292

57. Teach, Learn, and Make with Raspberry Pi - Raspberry Pi n.d. https://www.raspberrypi.org/ (accessed October 1, 2020)

58. Scientific computing tools for Python - SciPy.org (n.d.) https:// scipy.org/about.html. Accessed 1 Oct 2020

59. NI LabVIEW LINX Toolkit - National Instruments (n.d.). https:// sine.ni.com/nips/cds/view/p/lang/it/nid/218410. Accessed 1 Oct 2020

60. Programmazione di Raspberry Pi con MATLAB e Simulink (n.d.) https://it.mathworks.com/discovery/raspberry-pi-programmingmatlab-simulink.html (accessed October 7, 2020)

61. Mazzarisi M, Campanelli SL, Angelastro A, Dassisti M (2020) Phenomenological modelling of direct laser metal deposition for single tracks. Int J Adv Manuf Technol 111:1955-1970. https:// doi.org/10.1007/s00170-020-06204-x

62. Raspberry Pi 4 Model B specifications - Raspberry Pi (n.d.) https://www.raspberrypi.org/products/raspberry-pi-4-model-b/ specifications/ (accessed September 15, 2020)

63. Welcome to Python.org. PythonOrg (n.d.) https://www.python. org/ (accessed September 10, 2020)

64. Waqar S, Sun Q, Liu J, Guo K, Sun J (2021) Numerical investigation of thermal behavior and melt pool morphology in multitrack multi-layer selective laser melting of the 316L steel. Int J Adv Manuf Technol 112:879-895. https://doi.org/10.1007/ s00170-020-06360-0

65. SIEMENS. SENTRON PAC3200 - Reliable and precise monitoring of electrical power systems. Datasheet Available At: (n.d.) https://www.mc-mc.com/ASSETS/DOCUMENTS/ITEMS/EN/ Siemens_93_47ADAPTER_Datasheet.pdf (accessed March 27, 2020).

66. Whiting J, Springer A, Sciammarella F (2018) Real-time acoustic emission monitoring of powder mass flow rate for directed energy deposition. Addit Manuf 23:312-318. https://doi.org/10.1016/j. addma.2018.08.015

67. Errico V, Campanelli SL, Angelastro A, Mazzarisi M, Casalino G (2020) On the feasibility of AISI 304 stainless steel laser welding with metal powder. J Manuf Process 56:96-105. https://doi.org/ 10.1016/j.jmapro.2020.04.065

68. Reddy L, Preston SP, Shipway PH, Davis C, Hussain T (2018) Process parameter optimisation of laser clad iron based alloy: predictive models of deposition efficiency, porosity and dilution. Surf Coat Technol 349:198-207. https://doi.org/10.1016/j. surfcoat.2018.05.054

69. Mazzarisi M, Campanelli SL, Angelastro A, Palano F, Dassisti M (2020) In situ monitoring of direct laser metal deposition of a nickel-based superalloy using infrared thermography. Int J Adv Manuf Technol. https://doi.org/10.1007/s00170-020-06344-0

70. Kellens K, Baumers M, Gutowski TG, Flanagan W, Lifset R, Duflou JR (2017) Environmental dimensions of additive manufacturing: mapping application domains and their environmental implications: environmental dimensions of additive manufacturing. J Ind Ecol 21:S49-68. https://doi.org/10.1111/jiec.12629

Publisher's note Springer Nature remains neutral with regard to jurisdictional claims in published maps and institutional affiliations. 